\title{
Metal-Organic Framework MIL-53(Fe) as an Adsorbent for Ibuprofen Drug Removal from Aqueous Solutions: Response Surface Modeling and Optimization
}

\author{
Duyen Thi Cam Nguyen $\left(\mathrm{D},{ }^{1}\right.$ Hanh Thi Ngoc Le, ${ }^{2}$ Trung Sy Do, ${ }^{3}$ Van Thinh Pham, \\ Dai Lam Tran $\mathbb{D}^{5},{ }^{5}$ Van Thi Thanh Ho $\mathbb{D}^{6},{ }^{6}$ Thuan Van Tran $\mathbb{D}^{7},{ }^{7}$ Duy Chinh Nguyen $\mathbb{D}^{\circ}{ }^{7}$ \\ Trinh Duy Nguyen $\mathbb{D}^{7},{ }^{7}$ Long Giang Bach $\mathbb{D D}^{7}$ Huynh Ky Phuong Ha ${ }^{8},{ }^{8}$ \\ and Van Thuan Doan ${ }^{7}{ }^{7}$
}

${ }^{1}$ Faculty of Pharmacy, Nguyen Tat Thanh University, Ho Chi Minh City, Vietnam

${ }^{2}$ Institute of Hygiene and Public Health, Ho Chi Minh City, Vietnam

${ }^{3}$ Institute of Chemistry, Vietnam Academy of Science and Technology, Hanoi, Vietnam

${ }^{4}$ Dong Nai Technology University, Bien Hoa City, Dong Nai Province, Vietnam

${ }^{5}$ Institute for Tropical Technology, Vietnam Academy of Science and Technology, Hanoi, Vietnam

${ }^{6}$ Ho Chi Minh University of Natural Resources and Environment, Ho Chi Minh City, Vietnam

${ }^{7}$ NTT Hi-Tech Institute, Nguyen Tat Thanh University, Ho Chi Minh City, Vietnam

${ }^{8}$ Faculty of Chemical Engineering, Ho Chi Minh City University of Technology, Ho Chi Minh City, Vietnam

Correspondence should be addressed to Van Thuan Doan; doanthuanms@gmail.com

Received 1 December 2018; Revised 21 January 2019; Accepted 3 February 2019; Published 3 March 2019

Guest Editor: Nguayen Van Noi

Copyright (c) 2019 Duyen Thi Cam Nguyen et al. This is an open access article distributed under the Creative Commons Attribution License, which permits unrestricted use, distribution, and reproduction in any medium, provided the original work is properly cited.

\begin{abstract}
Ibuprofen contamination from water sources has been increasingly alarming due to its environmentally accumulative retention; however, the strategies for ibuprofen-containing water treatment are still an enormous challenge. Herein, we described the utilization of metal-organic frameworks MIL-53(Fe) ( MIL = Materials of Institute Lavoisier) for the adsorption of ibuprofen in synthetic solution. Firstly, the MIL-53(Fe) was solvothemally synthesized and then characterized using the X-ray diffraction and Fourier-transform infrared spectroscopy techniques. The optimization of ibuprofen adsorption over MIL-53(Fe) was performed with three independent variables including ibuprofen concentration (1.6-18.4 mg/L), adsorbent dosage $(0.16-1.84 \mathrm{~g} / \mathrm{L})$, and $\mathrm{pH}$ (2.6-9.4) according to the experimental design from response surface methodology. Under the optimized conditions, more than $80 \%$ of ibuprofen could be eliminated from water, indicating the promising potential of the MIL-53(Fe) material for treatment of this drug. Kinetic and isotherm models also were used to elucidate the chemisorption and monolayer behavior mechanisms of ibuprofen over MIL-53(Fe).
\end{abstract}

\section{Introduction}

Ibuprofen (( $\pm \mathrm{R}, \mathrm{S})-2-(4-(2-m e t h y l p r o p y l)$ phenyl)propanoic acid, IBU), a nonsteroidal anti-inflammatory drugs (NSAIDs), has widely been used for the treatment of bacterial infection-related diseases in many countries (its chemical structure is shown in Figure 1) [1-4]. However, there is a rapid acceleration in IBU contamination due to the ineffective treatment of wastewater sources, derived from hospitals and pharmaceutical manufacturers [5-7]. According to recent environmental reports, varying amounts of the IBU residue have been detected in some rivers (i.e., Thames River, UK $(0.783 \mu \mathrm{g} / \mathrm{L})$, and Aura River, Finland $(20 \mu \mathrm{g} / \mathrm{L}))$, significantly exceeding the permissible standards for human health [8]. Besides, the accumulation of the IBU pollutant in water may support 
<smiles>CC(C)Cc1ccc(C(C)C(=O)O)cc1</smiles>

Figure 1: 2D structure of the IBU molecule by ChemDraw ${ }^{\circledR}$ ultra 12.0 program.

the antibiotics-resistant bacteria existing in the environment $[1,5,9]$. Therefore, techniques for eliminating this contaminant have received a great attention.

Adsorption is often regarded as a common method for the removal of pollutants in gas and liquid phases [10-15]. Several strong points of this approach include costeffectiveness and high performance [16, 17]. Thanks to the good reusability of absorbents, the overall cost can be reduced. Moreover, the adsorption is highly compatible with organic-derived hazardous wastes including IBU contaminant [4]. Therefore, the IBU degradation by the adsorption process has been rapidly developed.

In the adsorption process, solid adsorbents play a decisive role in removing the contaminants [18]. Heterogeneous materials have undergone a long history, especially nanostructured zeolites and mesoporous silica [4, 19-22]. Thanks to the highly porous structure along with open metal sites, these materials have been considered as ideal platforms towards diverse applications in fuel cells, chemical sensing, energy conversion, catalysis, drug delivery, and thin films [23-25]. However, the synthesis strategies for such materials were carried out via many elaborate steps combined with severe condition-controlled reactions, limiting their widespread applications [26]. Several studies reported the use of hazardous and expensive agents (i.e., reversible additionfragmentation chain transfer (RAFT)) as vital components that control the growing of polymeric organic chains in controlled radical polymerizations, thus imposing the adverse impacts on the environment [26]. It is evident that finding out the greener and sustainable pathways for the fabrication of nanostructured materials is necessary.

Metal-organic frameworks (MOFs) are advanced materials constructed by metal ions or clusters and organic ligands via the coordination bonds [27-30]. Recently, they are considered as remarkable and promising materials because of good crystallinity, complex topologies, high porosity, tunable chemical properties, and large metal cluster density, and thereby, MOFs have attracted much attention in many fields such as drug delivery, catalysis, gas storage, sensor, and adsorption [31]. MIL-53(Fe) or Fe(III)(OH)(1,4$\mathrm{BDC})$ is a typical class of MOFs generated by a combination between iron(III) cations and 1,4-dicarboxylic acid [32, 33]. This structure consists of $\mathrm{FeO}_{6}$ hexagonal chains connecting with dicarboxylate anions to form the three-dimensional networks or SBUs (secondary building units) [34-36]. One of the most emergent features of MIL-53(Fe) compared with other MOFs is the "breathing effect," which experiences a breathing transition in the presence of guest molecules, thus creating the structural flexibility [37]. Moreover, this material can be easily synthesized via the conventional strategies, such as microwave or solvothermal method $[38,39]$. Unlike the other MOFs such as MIL- $88 \mathrm{~B}(\mathrm{Cr})$ or MIL-101(Cr), which also represents the same "breathing effect," MIL-53(Fe) is chemically stable and constituted of lower toxic metal centers and thus has gained much attention [40].

In this work, we described the MIL-53(Fe) synthesis by the solvothermal method and its application in IBU adsorption. Some techniques including XRD and FT-IR were used to analyze the as-synthesized products. Moreover, the experiments were optimized based on the response surface methodology.

\section{Experimental}

2.1. Chemicals and Instruments. All chemicals in this study were directly used without any purification. 1,4-Benzenedicarboxylic acid $\left(\mathrm{H}_{2} \mathrm{BDC}, 98 \%\right)$ was purchased from Merck. Iron(III) chloride hexahydrate $\left(\mathrm{FeCl}_{3} \cdot 6 \mathrm{H}_{2} \mathrm{O}, 99.0 \%\right)$, and $\mathrm{N}, \mathrm{N}$-dimethylformamide (DMF, 99.5\%) were purchased from Xilong Chemical, China.

The D8 Advance Bruker powder diffractometer was used to record the X-ray powder diffraction (XRD) profiles using $\mathrm{Cu}-\mathrm{K} \alpha$ beams as excitation sources. The FT-IR spectra were recorded on the Nicolet 6700 spectrophotometer to explore the functional groups. The UV-Vis spectrophotometer was used to determine the IBU concentration at wavelength $222 \mathrm{~nm}$. All analytic samples were reactivated at $105^{\circ} \mathrm{C}$ under nitrogen atmosphere.

2.2. Synthesis of $M I L-53(\mathrm{Fe})$. The MIL-53(Fe) was solvothermally prepared according to a recent study [37]. Firstly, $1.35 \mathrm{~g}$ of $\mathrm{FeCl}_{3} \cdot 6 \mathrm{H}_{2} \mathrm{O}$ and $0.83 \mathrm{~g}$ of $\mathrm{H}_{2} \mathrm{BDC}$ were dissolved in $25 \mathrm{~mL}$ DMF. The mixture was then transferred into a Teflon-lined autoclave and heated up at $150^{\circ} \mathrm{C}$ for $6 \mathrm{~h}$. The yellow solid was extracted, refluxed with DMF overnight, washed with $\mathrm{C}_{2} \mathrm{H}_{5} \mathrm{OH}$ for three times $(3 \times 10 \mathrm{~mL})$, and then dried at $80^{\circ} \mathrm{C}$ for storage in a desiccator. Figure 2 illustrates the synthesis strategy of MIL-53(Fe).

2.3. Experimental Batches. The stock solutions $(20 \mathrm{mg} / \mathrm{L})$ were prepared by dissolving the IBU substrate in distilled water. Various levels of concentration $(1.8-18.4 \mathrm{mg} / \mathrm{L})$ for the adsorption were generated by consecutively diluting the initial stock solutions. A series of $\mathrm{HCl}$ and $\mathrm{KOH}$ solutions was utilized to adjust the $\mathrm{pH}$ indexes. Herein, twenty experimental runs were randomly performed at room temperature following the response surface methodology (RSM) [42]. Firstly, MIL-53(Fe) samples $(0.16-1.84 \mathrm{~g} / \mathrm{L})$ were mixed with $50 \mathrm{~mL}$ of ibuprofen solutions $(1.8-18.4 \mathrm{mg} / \mathrm{L})$ at various ranges of $\mathrm{pH}$. The flasks were sealed and placed in the shaking tables $(200 \mathrm{rpm})$. After the adsorption process reached the equilibrium state at $120 \mathrm{~min}$, the adsorbent solids were dispended and separated using the simple centrifugation. The IBU residual concentrations were identified using UV-Vis spectroscopy at the wavelength of 


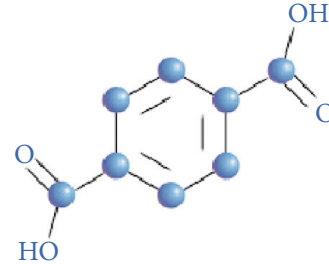

$1,4-\mathrm{BDC}$

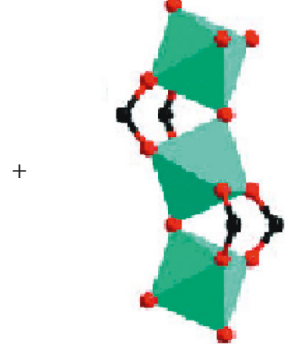

$\mathrm{FeCl}_{3} \cdot 6 \mathrm{H}_{2} \mathrm{O}$
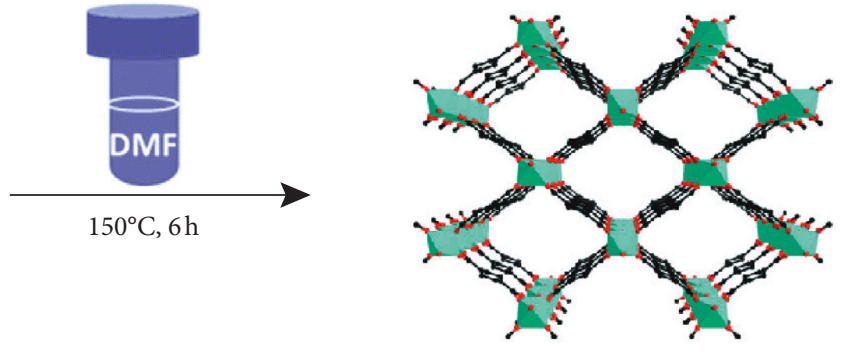

MIL-53(Fe)

Figure 2: Schematic illustration for the synthesis of the MIL-53(Fe). The simulated structure of MIL-53(Fe) and iron(III) clusters was reproduced from [41].

$222 \mathrm{~nm}$. The percentage of removal $y(\%)$ and adsorption capacity $Q(\mathrm{mg} / \mathrm{g})$ can be mathematically defined as follows:

$$
\begin{aligned}
y(\%) & =\frac{C_{0}-C_{\mathrm{e}}}{C_{0}} \cdot 100, \\
Q_{t} & =\frac{C_{0}-C_{t}}{m} \cdot V, \\
Q_{\mathrm{e}} & =\frac{C_{0}-C_{\mathrm{e}}}{m} \cdot V,
\end{aligned}
$$

where $C_{0}, C_{t}$, and $C_{\mathrm{e}}$ are denoted for the initial concentration, concentration at time $t(\mathrm{~min})$, and equilibrium concentrations $(\mathrm{mg} / \mathrm{L})$ and $m(\mathrm{~g})$ and $V(\mathrm{~mL})$ are denoted for adsorbent mass and solution volume, respectively.

\subsection{Optimization Model with Response Surface Methodology.}

Response surface methodology is the empirically statistical method, which allows optimizing the target $(y)$ or "response" based on the evaluation of chosen variables $\left(x_{i}\right)$ [43]. In this study, three factors as input parameters were selected to investigate including IBU concentration $\left(x_{1}\right)$, MIL-53 dosage $\left(x_{2}\right)$, and $\mathrm{pH}\left(x_{3}\right)$. Their random experimental runs were designed according to the guide of the Design-Expert version 10 (DX10) program (Table 1).

The "response" of the model was the removal efficiency $(y)$, and thus, the target of this model is to maximize the "response"; the function of three variables is given by the following equation:

$$
y=f(x)=\beta_{\mathrm{o}}+\sum_{i=1}^{k} \beta_{i} x_{i}+\sum_{i=1}^{k} \sum_{j=1}^{k} \beta_{i j} x_{i} x_{j}+\sum_{i=1}^{k} \beta_{i i} x_{i}^{2}
$$

where $y$ is the predicted response and $x_{i}$ and $x_{j}$ are the independent variables $(i, j=1,2,3,4, \ldots, k)$. The parameter $\beta_{\mathrm{o}}$ is the offset coefficient, $\beta_{i}$ is the linear coefficient, $\beta_{i i}$ is the second-order coefficient, and $\beta_{i j}$ is the interaction coefficient [44].

2.5. Error Analysis. In this study, we explored the nonlinear kinetic and isotherm models using error functions, which were fitted by the Origin 9.0 program. Error analysis aims to determine the suitability of any models, and their confidence level could be assessed via commonplace error functions
TABLE 1: List of independent variables and their levels.

\begin{tabular}{lccccccc}
\hline \multirow{2}{*}{ Factors } & \multirow{2}{*}{ Unit } & \multirow{2}{*}{ Code } & \multicolumn{5}{c}{ Levels } \\
& & & $-\alpha$ & -1 & 0 & +1 & $+\alpha$ \\
\hline Initial concentration & $\mathrm{mg} / \mathrm{L}$ & $x_{1}$ & 1.6 & 5 & 10 & 15 & 18.4 \\
Adsorbent dosage & $\mathrm{g} / \mathrm{L}$ & $x_{2}$ & 0.16 & 0.5 & 1 & 1.5 & 1.84 \\
$\mathrm{pH}$ & - & $x_{3}$ & 2.6 & 4 & 6 & 8 & 9.4 \\
\hline
\end{tabular}

[45]. Thus, coefficient of determination $\left(R^{2}\right)$, mean relative error (MRE), and sum square error (SSE) were used, and their mathematical forms were shown in equations (3)-(5). Moreover, $Q_{i, \text { cal }}$ and $Q_{i \text {,exp }}$ are the respective calculated and experimental adsorption capacity values:

$$
R^{2}=\frac{\sum_{i=1}^{n}\left(Q_{i, \exp }-\overline{Q_{i, \exp }}\right)^{2}-\sum_{i=1}^{n}\left(Q_{i, \exp }-\overline{Q_{i, \text { cal }}}\right)^{2}}{\sum_{i=1}^{n}\left(Q_{i, \exp }-\overline{Q_{i, \exp }}\right)^{2}},
$$

$$
\begin{aligned}
\operatorname{MRE}(\%) & =\frac{100}{n} \sum_{i=1}^{n}\left|\frac{Q_{i, \text { cal }}-Q_{i, \exp }}{Q_{i, \exp }}\right|, \\
\text { SSE } & =\sum_{i=1}^{n}\left(Q_{i, \text { cal }}-Q_{i, \exp }\right)^{2} .
\end{aligned}
$$

\section{Results and Discussion}

3.1. Structural Characterization of MIL-53( $\mathrm{Fe})$. Figure 3 describes the structural characterization of MIL-53(Fe) using the X-ray diffraction patterns and FT-IR spectra. According to Figure 3(a), several emerging peaks were found at scanning degree of $9.5^{\circ}(101), 18.6^{\circ}(002)$, and $28.2^{\circ}(302)$, indicating that the MIL-53(Fe) obtained a crystalline structure. This observation was also commensurate with several previous reports [33,46,47], suggesting that the MIL-53(Fe) was solvothermally synthesized.

Moreover, the FT-IR spectrum in Figure 3(b) reveals the collection of functional groups that features the structure of MIL-53(Fe) (Table 2) [48]. In detail, a broad vibration at around $3420 \mathrm{~cm}^{-1}$ was ascribed to the presence of $\mathrm{O}-\mathrm{H}$ groups, which adsorbed water existing in the surface of MIL53(Fe) [49]. The asymmetric ( $\left.\gamma_{\text {as }} \mathrm{C}-\mathrm{O}\right)$ and symmetric $\left(\gamma_{\mathrm{s}} \mathrm{C}-\mathrm{O}\right)$ stretching of dicarboxylate linkers could be verified 


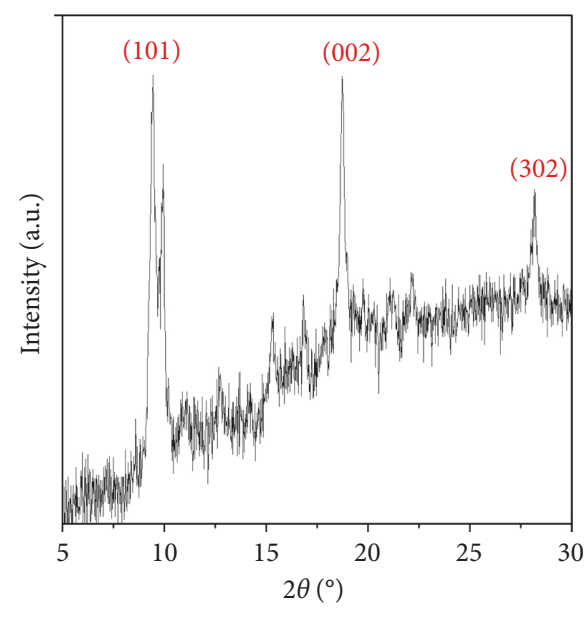

(a)

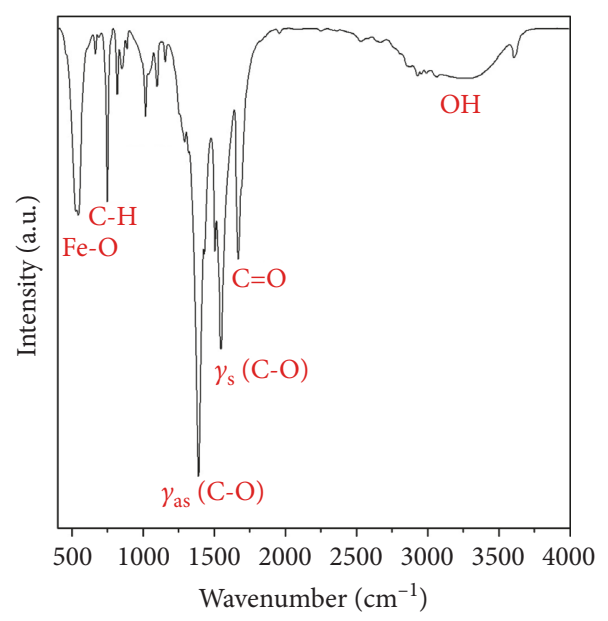

(b)

FIgURe 3: X-ray diffraction patterns (a) and FT-IR spectra of MIL-53(Fe) (b).

TABLE 2: The surface functional groups analysis of MIL-53(Fe).

\begin{tabular}{lcccccc}
\hline Functional groups & $\mathrm{O}-\mathrm{H}$ & $\mathrm{C}=\mathrm{O}$ & $\gamma_{\text {as }}(\mathrm{C}-\mathrm{O})$ & $\gamma_{\mathrm{s}}(\mathrm{C}-\mathrm{O})$ & $\mathrm{C}-\mathrm{H}$ & $\mathrm{Fe}-\mathrm{O}$ \\
\hline Wavenumber $\left(\mathrm{cm}^{-1}\right)$ & 3420 & 1678 & 1550 & 1390 & 745 & 540 \\
\hline
\end{tabular}

by the appearance of sharp vibrations at $1550 \mathrm{~cm}^{-1}$ and $1390 \mathrm{~cm}^{-1}$, respectively, [37]. Moreover, the carbonyl groups $(\mathrm{C}=\mathrm{O})$ of carboxylate ligand $(\mathrm{COO})$ were visible at $1678 \mathrm{~cm}^{-1}$, whereas a very sharp peak at $745 \mathrm{~cm}^{-1}$ was consistently corresponding to $\mathrm{Csp}^{2}-\mathrm{H}$ bending vibrations, which belong to the aromatic rings of carboxylates [50]. Especially, the characteristic coordination bonds between $\mathrm{Fe}^{3+}$ cations and -OOC- $\mathrm{C}_{6} \mathrm{H}_{4}$ - $\mathrm{COO}-$ carboxylate anions were observed at the low wavenumber $\left(540 \mathrm{~cm}^{-1}\right)$, revealing the existence of a Fe-oxo bond inherent in the structure of MIL-53(Fe) [51]. Therefore, a combination of two characterization results demonstrates that the crystals of MIL$53(\mathrm{Fe})$ were successfully fabricated.

The morphological properties of MIL-53(Fe) can be analyzed by the SEM technique. Figure 4 showed the MIL$53(\mathrm{Fe})$ particles at 100 and $10 \mu \mathrm{m}$, which generally welldescribed the polyhedron-like crystalline structure [32]. However, a clear difference of MIL-53(Fe) samples could be observed between before and after purification. Figure 4(b) demonstrated that a certain part of as-synthesized MIL$53(\mathrm{Fe})$ morphology was not homogeneous, which may be attributable to the residual 1,4-BDC components. A previous study also implied that this precursor may encapsulate the assynthesized MIL-53(Fe) crystals [52]. Meanwhile, Figure 4(c) showed a relatively smooth surface of refined MIL-53(Fe) along with the complete disappearance of amorphous solid phases, suggesting that the refinement of as-synthesized MIL$53(\mathrm{Fe})$ was necessary to eliminate the 1,4-BDC trace [52].

Figure 5(a) diagnosed the textual feature of MIL-53(Fe) using the Raman spectrum. Clearly, a shape peak could be observed at the Raman shift of $464 \mathrm{~cm}^{-1}$, revealing the existence of gamma bond of $\mathrm{Fe}$-oxo in the structure of MIL-53(Fe). Also, typical peaks of the aromatic C-H bond were found at 632 and $865 \mathrm{~cm}^{-1}$, while the single peak at
$1141 \mathrm{~cm}^{-1}$ was ascribed for the bonds between two $\mathrm{sp}^{2}$ hydrid carbon atoms of benzene rings and carboxylate groups. Importantly, the asymmetric $\left(\gamma_{\mathrm{as}} \mathrm{C}-\mathrm{O}\right)$ and symmetric $\left(\gamma_{s} \mathrm{C}-\mathrm{O}\right)$ footprints of $\mathrm{COO}$ - linkers were again confirmed via a couple of consecutive peaks at 1451 and $1501 \mathrm{~cm}^{-1}$, respectively. Finally, $v(\mathrm{C}=\mathrm{C})$ was a kind of typical bond of aromatic cycles, which were emergent at $1616 \mathrm{~cm}^{-1}$.

To gain the insights into the nature of porosity and pore size in MIL-53(Fe), the pore size distribution was measured and shown in Figure 5(b). It is evident that pore diameters of MIL-53(Fe) exhibited a wide range of sizes, revealing the existence of both micropore and macropore in the structure, but macrosize pore (more than $50 \mathrm{~nm}$ ) was utterly dominant. Notice that there was an infinitesimal amount of micropore, which was less than $2 \mathrm{~nm}$ in length. Moreover, the surface area of MIL-53(Fe) was determined by the $\mathrm{N}_{2}$ adsorption-desorption isotherm at $77 \mathrm{~K}$, which was found to be $5.5 \mathrm{~m}^{2} / \mathrm{g}$. Tuan et al. also reported the very low surface area, at about $14 \mathrm{~m}^{2} / \mathrm{g}$, which may be attributable to the closed pores of MIL-53(Fe) that prevent the arrival of nitrogen molecules [49].

3.2. Optimization of the Ibuprofen Absorbability of MIL53(Fe) by RSM Tool. Herein, we applied the RSM to optimize the removal of IBU in water using the MIL-53(Fe) as an adsorbent. All experiments were designed and analyzed statistically using the DX10 [11]. In detail, three independent variables including initial IBU concentration, MIL-53(Fe) adsorbent dosage, and $\mathrm{pH}$ solution at various five levels were investigated. The relationship between IBU removal efficiency and three independent variables can be described by the following equation: 

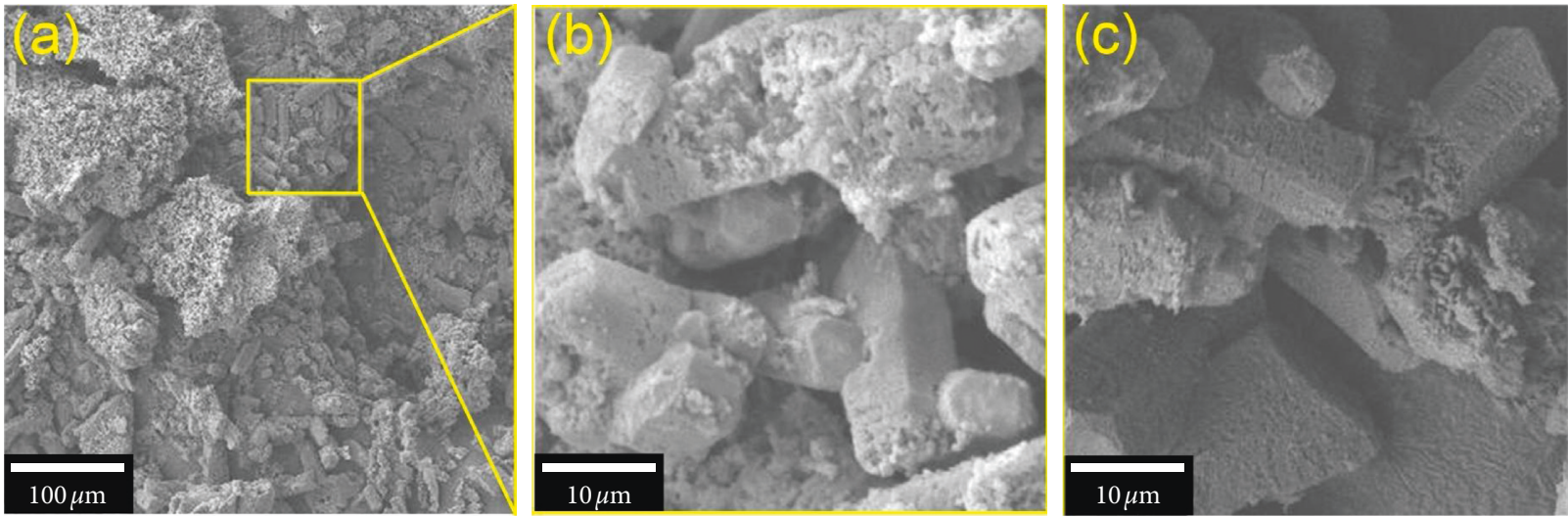

Figure 4: SEM images of MIL-53(Fe) before ( $a, b)$ and after refinement (c).

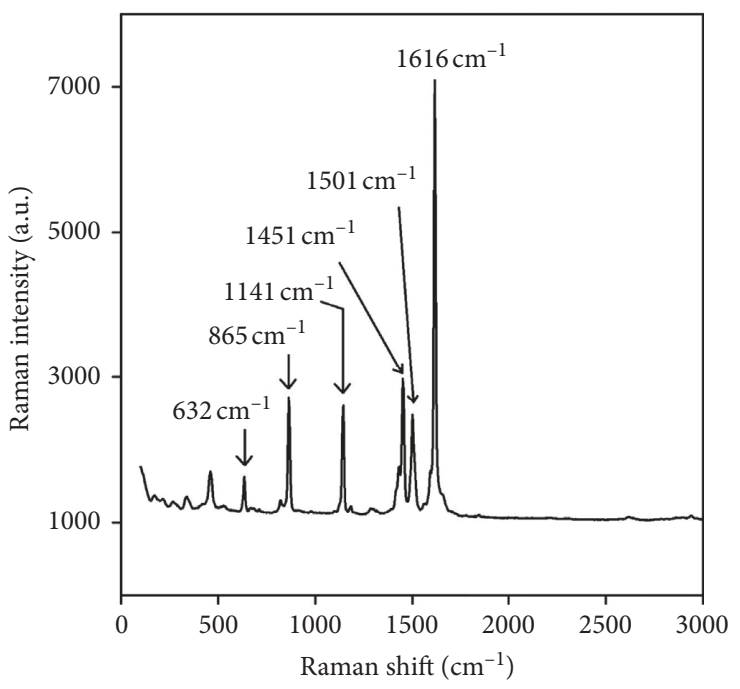

(a)

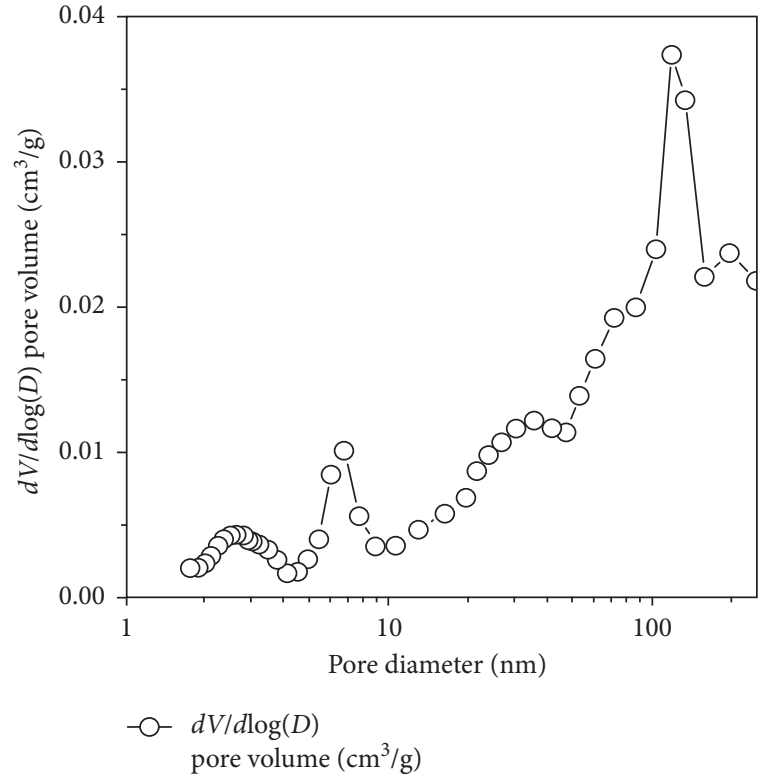

(b)

FIGURE 5: Raman spectrum (a) and pore size distribution (b) of MIL-53(Fe).

$$
\begin{aligned}
y(\%)= & 21.56-5.21 x_{1}+7.15 x_{2}-19.58 x_{3} \\
& +6.83 x_{1} x_{2}+0.88 x_{1} x_{3}-4.35 x_{2} x_{3} \\
& +4.97 x_{1}^{2}+5.69 x_{2}^{2}+11.10 x_{3}^{2}, \\
\text { or IBU removal }(\%)= & 21.56-5.21(C)+7.15(\text { dose }) \\
& -19.58(\mathrm{pH})+6.83(C)(\text { dose }) \\
& +0.88(C)(\mathrm{pH}) \\
& -4.35(\text { dose })(\mathrm{pH})+4.97(C)^{2} \\
& +5.69(\text { dose })^{2}+11.10(\mathrm{pH})^{2} .
\end{aligned}
$$

The actual and predicted values for the experimental matrix were listed in Table 3. Table 4 illustrates the coefficients of ANOVA data including the sum of squares, degree of freedom, mean square, $F$ value, and Prob. $>F$ [43].
Interestingly, determination coefficients $\left(R^{2}\right)$ and $P$ values of the regression model were found to be 0.9621 and $<0.0001$ with the confidence level of $95 \%$, respectively. Thus, the proposed quadratic model was statistically significant and could be used to assess the effect of factors (initial IBU concentration, MIL-53(Fe) adsorbent dosage and $\mathrm{pH}$ ) on the IBU absorbability of MIL-53(Fe) [48]. Figure 6(a) also indicates the high compatibility of experimental and predicted values as their data points were closely distributed to the 45 degree line.

Figures 6(b)-6(d) showing the three-dimensional response surfaces reveal the consistent impacts of three factors on the IBU drug removal efficiencies of MIL-53(Fe). Generally, the removal process of IBU was conducive with an increase in the amount of the MIL-53 adsorbent or a decrease in $\mathrm{pH}$ values of IBU solutions. Meanwhile, the initial concentration of IBU solution shows a negligible effect on the IBU removal efficiency. 
TABLE 3: Experimental design used for investigation of IBU removal over MIL-53(Fe).

\begin{tabular}{lccccc}
\hline & \multicolumn{3}{c}{ Variables } & \multicolumn{2}{c}{ IBU removal } \\
$N$ & $x_{1}$ & $x_{2}$ & $x_{3}$ & Observed & Predicted \\
\hline 1 & 5 & 0.5 & 4 & 69.8 & 64.3 \\
2 & 15 & 0.5 & 4 & 43.8 & 38.5 \\
3 & 5 & 1.5 & 4 & 80 & 73.7 \\
4 & 15 & 1.5 & 4 & 78.7 & 75.1 \\
5 & 5 & 0.5 & 8 & 35.8 & 32.1 \\
6 & 15 & 0.5 & 8 & 10.7 & 9.8 \\
7 & 5 & 1.5 & 8 & 26 & 24.1 \\
8 & 15 & 1.5 & 8 & 30.8 & 29.0 \\
9 & 1.6 & 1 & 6 & 37.5 & 44.4 \\
10 & 18.4 & 1 & 6 & 23.5 & 26.9 \\
11 & 10 & 0.16 & 6 & 20 & 25.6 \\
12 & 10 & 1.84 & 6 & 45.1 & 49.7 \\
13 & 10 & 1 & 2.6 & 77.1 & 85.9 \\
14 & 10 & 1 & 10.4 & 18.6 & 20.0 \\
15 & 10 & 1 & 6 & 22.6 & 21.6 \\
16 & 10 & 1 & 6 & 17.7 & 21.6 \\
17 & 10 & 1 & 6 & 23.8 & 21.6 \\
18 & 10 & 1 & 6 & 25 & 21.6 \\
19 & 10 & 1 & 6 & 20 & 21.6 \\
20 & 10 & 1 & 6 & 22 & 21.6 \\
\hline
\end{tabular}

Understandably, the improvement of IBU removal percentage may be ascribed to the presence of "adsorption sites" [53]. When an addition of adsorbent was considerable, "adsorption sites" containing the surface functional groups became more dominant, thus increasing the number of IBU molecules captured $[54,55]$. By contrast, a decline in the amount of the MIL-53(Fe) adsorbent may result in the rapid saturation of adsorption sites, possibly rendering the treatment of IBU drug ineffective.

Importantly, the decontamination of the IBU pollutant reached the excellent results in the acidic media, while the figures for the basic/neutral solutions were clearly unfavorable. In detail, Figure 6(d) indicates that nearly $100 \%$ of IBU could be removed from water at the very low $\mathrm{pH}$ values (i.e., $\mathrm{pH}=2.6-4.3)$ and high adsorbent dosage (1.5-1.84 g/L).

By applying the RSM via model confirmation, several optimal conditions were proposed including the factors along with the predicted response value (Table 5). To test the precision and confidence of proposed optimized conditions, a verification experiment was performed using the above proposed conditions. The observed results were in good agreement with the predicted results because there was an ineligible error between predicted and tested results, and "desirability" values were obtained up to $100 \%$, reflecting the excellent closeness of response $(y)$ to their ideal values [56]. In other words, the model for the optimization of IBU adsorption over MIL-53(Fe) in this study achieved the high compatibility and thus could be used to design and optimize the experimental conditions.

3.3. Adsorption Studies. To gain deeper insights into the adsorption mechanism and behavior of IBU over
MIL-53(Fe), herein, the nonlinear kinetic and isotherm models could be adopted. All experiments were conducted at room temperature, and other experimental conditions were chosen from model optimization (Table 5), at initial concentration $(10 \mathrm{mg} / \mathrm{L})$, dosage $(1.0 \mathrm{~g} / \mathrm{L})$, and $\mathrm{pH} 2.6$. Note that samples were extracted for regular time intervals $(0,10,20$, $40,60,80,100$, and $120 \mathrm{~min}$ ) to investigate the kinetic study, while IBU concentrations were in range from 5 to $20 \mathrm{mg} / \mathrm{L}$. Final IBU content could be measured by using a UV-Vis spectrophotometer at $222 \mathrm{~nm}$.

Any selected model needs to meet the requirements in terms of $R^{2}$, MRE (\%), and SSE. A model with a high $R^{2}$ value indicates that the predicted data are fitted well with actual data [45]. Meanwhile, lower MRE and SSE values reveal the negligible magnitude of error functions. To assess the models, therefore, terms of $R^{2}$, MRE (\%), and SSE were added herein.

For the kinetic models, we optioned four equations including pseudo-first-order, pseudo-second-order, Elovich, and Bangham, which their mathematical forms were illustrated in the equations given in Table 6. Figure 7(a) illustrates the effect of uptake capacity on contact time. It is evident that the adsorption process reached an equilibrium nature after $90 \mathrm{~min}$. According to Table 6, all kinetic models obtained an excellent fitness based on $R^{2}$ values (0.9810.992 ), indicating the high compatibility between actual and proposed data. Nevertheless, among the models, the pseudosecond-order equation offered the highest degree of suitability because of the highest $R^{2}$, smallest SSE, and very low MRE (\%). In fact, Elovich model showed the lowest MRE (3.15\%), but its SSE value was so far higher than the pseudosecond-order model, 7.44 compared with 0.39 , respectively. Therefore, the pseudo-second-order model could be used to explore the adsorption mechanism of the IBU species onto the adsorbent, which chemisorption plays a crucial role.

For the isotherm models, four equations including Langmuir, Freundlich, Temkin, and Dubinin and Radushkevich (D-R) were applied. Similar to the kinetic models, their mathematical forms were explained in equations given in Table 7. Obviously, the Langmuir demonstrated the most appropriate model via the highest $R^{2}$ and lowest MRE and SSE values, suggesting that the monolayer mechanism is more inclining to others. The maximum adsorption capacity $\left(Q_{\mathrm{m}}\right)$ obtained from the Langmuir equation was calculated at $10.67 \mathrm{mg} / \mathrm{g}$, revealing the favorable adsorption and good capacity of IBU onto MIL-53(Fe).

\section{Conclusion}

The MIL-53(Fe) material was successfully synthesized from the precursors including $\mathrm{FeCl}_{3} \cdot 6 \mathrm{H}_{2} \mathrm{O}$ and 1,4-BDC via the solvothermal method and structurally characterized using the X-ray diffraction patterns, FT-IR spectra, SEM, pore size distribution, and Raman. The characterization results implied that the MIL-53( $\mathrm{Fe})$ possessed the crystalline structure, along with a low surface area $\left(5.5 \mathrm{~m}^{2} / \mathrm{g}\right)$. Moreover, important functional groups were found $(\mathrm{Fe}-\mathrm{O}, \mathrm{COO}, \mathrm{C}=\mathrm{O}$, $\mathrm{C}-\mathrm{O}, \mathrm{C}-\mathrm{H}$, and $\mathrm{O}-\mathrm{H}$ ), proving the presence of these chemical bonds in the structure of MIL-53(Fe). For the optimization 
TABLE 4: ANOVA data for the IBU removal models.

\begin{tabular}{|c|c|c|c|c|c|c|}
\hline Source & Sum of squares & Freedom degree & Mean square & $F$ value & Prob. $>F$ & Note \\
\hline Model & 9093.12 & 9 & 1010.35 & 28.18 & $<0.0001^{\mathrm{S}}$ & \\
\hline$x_{1}$ & 370.63 & 1 & 370.63 & 10.34 & $0.0093^{S}$ & \\
\hline$x_{2}$ & 697.69 & 1 & 697.69 & 19.46 & $0.0013^{\mathrm{S}}$ & \\
\hline$x_{3}$ & 5235.08 & 1 & 5235.08 & 146.00 & $<0.0001^{\mathrm{S}}$ & \\
\hline$\left(x_{1}\right)^{2}$ & 372.65 & 1 & 372.65 & 10.39 & $0.0091^{\mathrm{S}}$ & ${ }^{\mathrm{S}}$ Significant at $p<0.05$ \\
\hline$\left(x_{2}\right)^{2}$ & 6.13 & 1 & 6.13 & 0.1708 & $0.6881^{\mathrm{N}}$ & ${ }^{\mathrm{N}}$ Nonsignificant at $p>0.05$ \\
\hline$\left(x_{3}\right)^{2}$ & 151.38 & 1 & 151.38 & 4.22 & $0.0670^{\mathrm{N}}$ & \\
\hline$x_{1} \cdot x_{2}$ & 356.18 & 1 & 356.18 & 9.93 & $0.0103^{\mathrm{S}}$ & \\
\hline$x_{1} \cdot x_{3}$ & 467.61 & 1 & 467.61 & 13.04 & $0.0048^{\mathrm{S}}$ & \\
\hline$x_{2} \cdot x_{3}$ & 1777.41 & 1 & 1777.41 & 49.57 & $<0.0001^{\mathrm{S}}$ & \\
\hline
\end{tabular}

Fit statistics: standard deviations $($ Std. $)=3.17$; mean $=36.43 ; \mathrm{CV}(\%)=16.44 ; R^{2}=0.9621$.

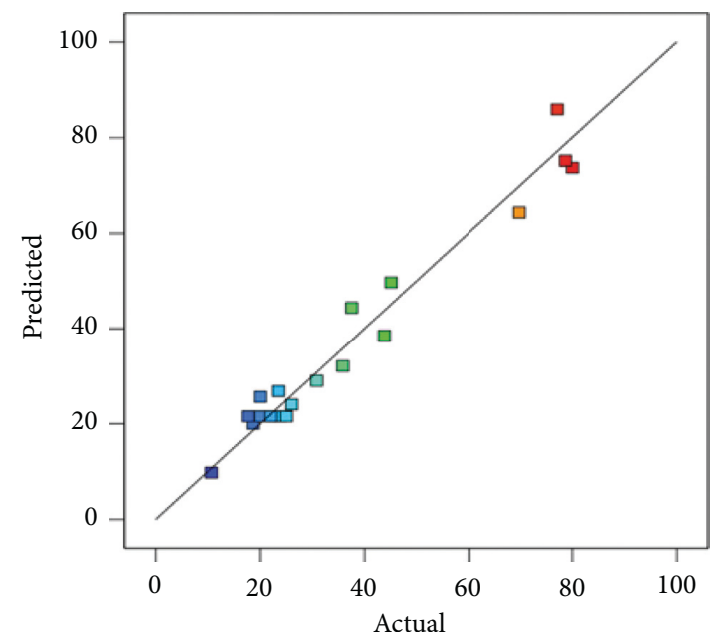

$10.7 \square 0$

(a)

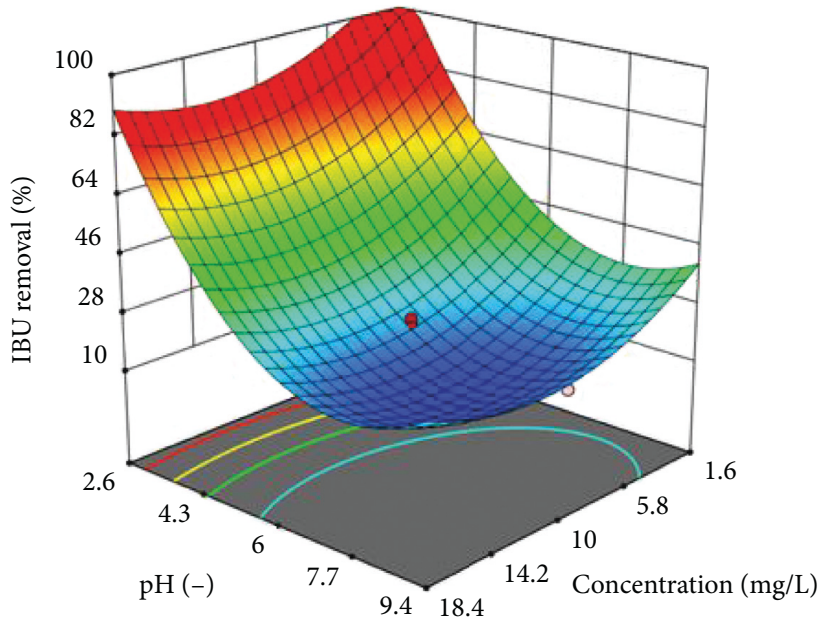

(c)

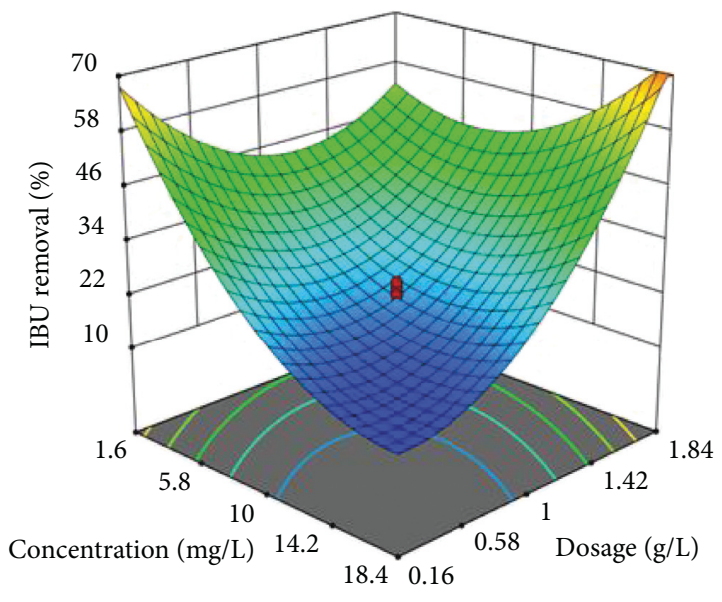

(b)

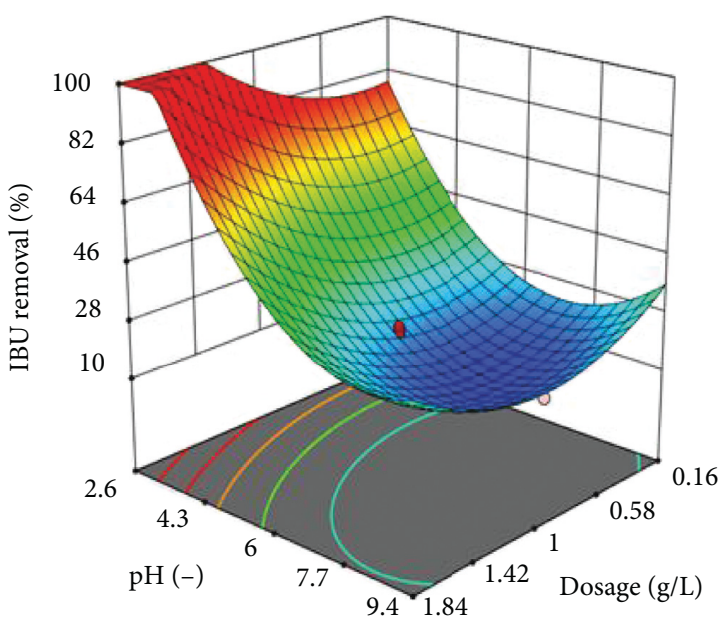

(d)

FIGURE 6: Actual versus predicted plots (a) and three-dimensional response surfaces (b)-(d) presenting the effect of factors on the response.

experiment of ibuprofen over MIL-53(Fe), the RSM results indicated that all variables (IBU initial concentration, MIL$53(\mathrm{Fe})$ dosage, and $\mathrm{pH}$ had a vital impact on the IBU removal efficiency through the very high determination of coefficient $\left(R^{2}>0.9\right)$ and very low $P$ value $(P<0.0001)$. Also, the proposed model was statistically significant and could be used to find out the optimal conditions. The confirmation tests also proved that the model was highly compatible with experimental data because the observed values was consistent with the predicted values and high removal efficiency 
TABLE 5: Optimal conditions and confirmation runs.

\begin{tabular}{|c|c|c|c|c|c|c|}
\hline \multirow{2}{*}{ Concentration (mg/L) } & \multirow{2}{*}{ Dosage $(\mathrm{g} / \mathrm{L})$} & \multirow{2}{*}{$\mathrm{pH}(-)$} & \multicolumn{3}{|c|}{ IBU removal efficiency (\%) } & \multirow{2}{*}{ "Desirability" } \\
\hline & & & Predicted (\%) & Tested (\%) & Error (\%) & \\
\hline 5.47 & 0.67 & 3.0 & 82.3 & 80.2 & -2.55 & 1.0000 \\
\hline 10.00 & 1.00 & 2.6 & 85.9 & 80.8 & -5.94 & 1.0000 \\
\hline 8.11 & 1.51 & 3.5 & 83.2 & 80.0 & -3.73 & 1.0000 \\
\hline
\end{tabular}

TABLE 6: Nonlinear kinetic constants for the adsorption of IBU over MIL-53(Fe).

\begin{tabular}{|c|c|c|c|}
\hline Kinetic models & Equation & Parameters & Value \\
\hline Pseudo-first-order & $Q_{t}=Q_{1} \cdot\left(1-\exp \left(-k_{1} t\right)\right)$ & $\begin{array}{c}k_{1}\left(\mathrm{~min}^{-1}\right) \\
Q_{1}(\mathrm{mg} / \mathrm{g}) \\
\operatorname{MRE~}(\%) \\
\text { SSE } \\
\left(R_{\mathrm{adj}}\right)^{2}\end{array}$ & $\begin{array}{c}0.0496 \\
7.87 \\
5.29 \\
0.83 \\
0.983 \\
\end{array}$ \\
\hline Pseudo-second-order & $\begin{array}{c}Q_{t}=t /\left(\left(1 / k_{2} Q_{2}^{2}\right)+\left(t / Q_{2}\right)\right) \\
H=k_{2} \cdot Q_{2}^{2}\end{array}$ & $\begin{array}{c}k_{2}(\mathrm{~g} / \mathrm{mg} \cdot \mathrm{min}) \\
Q_{2}(\mathrm{mg} / \mathrm{g}) \\
H(\mathrm{mg} / \mathrm{g} \cdot \mathrm{min}) \\
\mathrm{MRE}(\%) \\
\mathrm{SSE} \\
\left(R_{\mathrm{adj}}\right)^{2}\end{array}$ & $\begin{array}{c}0.0063 \\
9.28 \\
0.543 \\
3.67 \\
0.39 \\
0.992 \\
\end{array}$ \\
\hline Elovich & $Q_{t}=(1 / \beta)(\ln (1+\alpha \beta t))$ & $\begin{array}{c}\alpha(\mathrm{mg} / \mathrm{g} \cdot \mathrm{min}) \\
\beta(\mathrm{g} / \mathrm{mg}) \\
\mathrm{MRE}(\%) \\
\mathrm{SSE} \\
\left(R_{\mathrm{adj}}\right)^{2} \\
\end{array}$ & $\begin{array}{c}1.1 \\
0.5 \\
3.15 \\
7.44 \\
0.989 \\
\end{array}$ \\
\hline Bangham & $Q_{t}=k_{\mathrm{B}} \cdot t^{\alpha_{\mathrm{B}}}$ & $\begin{array}{c}k_{\mathrm{B}}(\mathrm{mL} /(\mathrm{g} / \mathrm{L})) \\
\alpha_{\mathrm{B}} \\
\operatorname{MRE}(\%) \\
\mathrm{SSE} \\
\left(R_{\mathrm{adj}}\right)^{2}\end{array}$ & $\begin{array}{c}1.98 \\
0.30 \\
5.02 \\
13.05 \\
0.981 \\
\end{array}$ \\
\hline
\end{tabular}

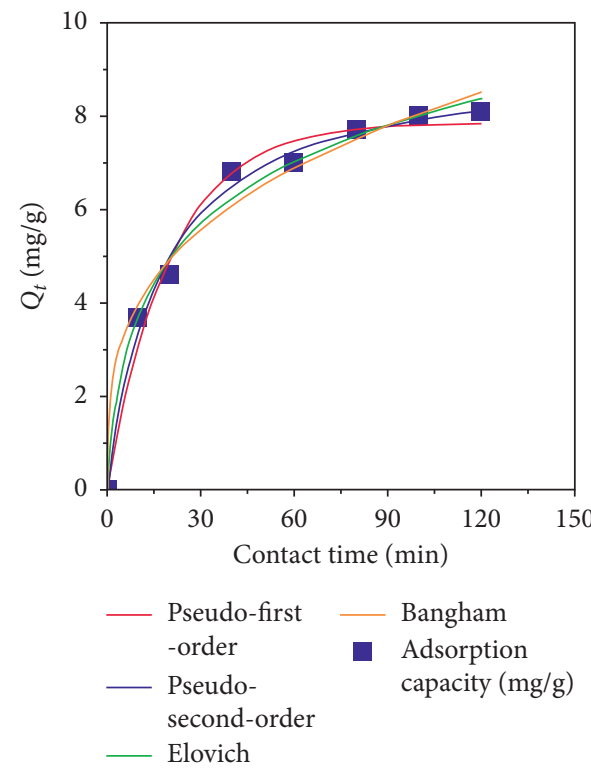

(a)
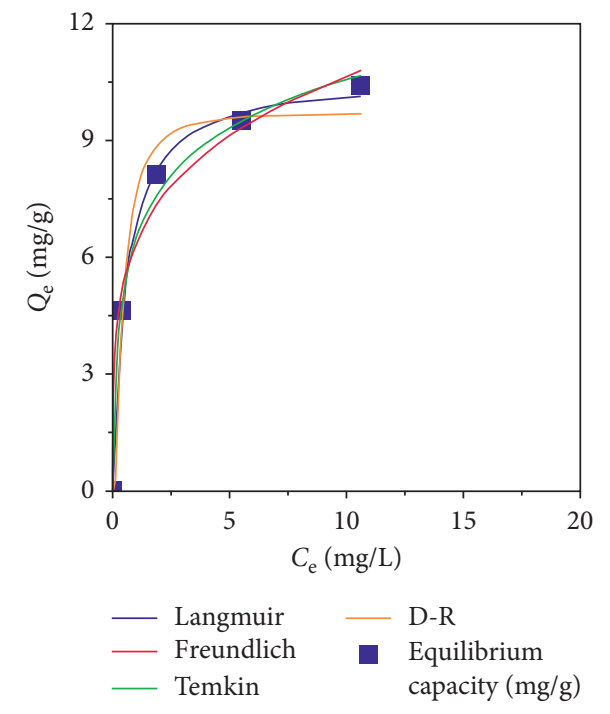

(b)

FIGURE 7: Kinetic and isotherm models for adsorption of IBU onto MIL-53(Fe). Experimental conditions consisted of initial concentration $(10 \mathrm{mg} / \mathrm{L})$, dosage $(1.0 \mathrm{~g} / \mathrm{L})$, and $\mathrm{pH} 2.6$ at room temperature. 
TABLE 7: Nonlinear isotherm constants for the adsorption of IBU over MIL-53(Fe).

\begin{tabular}{|c|c|c|c|}
\hline Kinetic models & Equation & Parameters & Value \\
\hline \multirow{6}{*}{ Langmuir } & \multirow{6}{*}{$\begin{array}{c}Q_{\mathrm{e}}=\left(Q_{\mathrm{m}} K_{\mathrm{L}} C_{\mathrm{e}}\right) /\left(1+K_{\mathrm{L}} C_{\mathrm{e}}\right) \\
R_{\mathrm{L}}=1 /\left(1+K_{\mathrm{L}} C_{\mathrm{o}}\right)\end{array}$} & $k_{\mathrm{L}}(\mathrm{L} / \mathrm{mg})$ & 1.80 \\
\hline & & $Q_{\mathrm{m}}(\mathrm{mg} / \mathrm{g})$ & 10.67 \\
\hline & & $R_{\mathrm{L}}$ & 0.03 \\
\hline & & $\operatorname{MRE}(\%)$ & 2.46 \\
\hline & & SSE & 0.18 \\
\hline & & $\left(R_{\text {adj }}\right)^{2}$ & 0.997 \\
\hline \multirow{5}{*}{ Freundlich } & \multirow{5}{*}{$Q_{\mathrm{e}}=K_{\mathrm{F}} C_{\mathrm{e}}^{1 / n}$} & $k_{\mathrm{F}}(\mathrm{mg} / \mathrm{g}) /(\mathrm{mg} / \mathrm{L})^{1 / n}$ & 6.39 \\
\hline & & $1 / n$ & 0.22 \\
\hline & & MRE (\%) & 6.43 \\
\hline & & SSE & 0.98 \\
\hline & & $\left(R_{\mathrm{adj}}\right)^{2}$ & $\begin{array}{l}0.90 \\
0.980 \\
\end{array}$ \\
\hline \multirow{5}{*}{ Temkin } & \multirow{5}{*}{$\begin{array}{c}Q_{\mathrm{e}}=B_{\mathrm{T}} \ln \left(k_{\mathrm{T}} C_{\mathrm{e}}\right) \\
B_{\mathrm{T}}=(R T) / b\end{array}$} & $k_{\mathrm{T}}(\mathrm{L} / \mathrm{mg})$ & 39.24 \\
\hline & & $B_{\mathrm{T}}$ & 1.77 \\
\hline & & MRE (\%) & 3.13 \\
\hline & & SSE & 0.31 \\
\hline & & $\left(R_{\mathrm{adj}}\right)^{2}$ & 0.993 \\
\hline \multirow{6}{*}{$\mathrm{D}-\mathrm{R}$} & \multirow{6}{*}{$\begin{array}{c}Q_{\mathrm{e}}=Q_{\mathrm{m}} \exp \left(-B \varepsilon^{2}\right) \varepsilon=R T \ln \left(1+\left(1 / C_{\mathrm{e}}\right)\right) \\
E=1 /(\sqrt{2 B})\end{array}$} & $B$ & 0.08 \\
\hline & & $Q_{\mathrm{m}}(\mathrm{mg} / \mathrm{g})$ & 9.72 \\
\hline & & $E(\mathrm{~kJ} / \mathrm{mol})$ & 2.47 \\
\hline & & MRE (\%) & 5.34 \\
\hline & & SSE & 1.18 \\
\hline & & $\left(R_{\mathrm{adj}}\right)^{2}$ & 0.978 \\
\hline
\end{tabular}

obtained (80.0-80.8\%). Kinetic and isotherm models also suggested that the adsorption process obeyed the chemisorption and monolayer behavior mechanisms.

\section{Data Availability}

No data were used to support this study.

\section{Conflicts of Interest}

The authors declare that there are no conflicts of interest.

\section{Acknowledgments}

This research was funded by NTTU Foundation for Science \& Technology Development (Grant no. 2018.01.15/HĐKHCN) and Center of Science and Technology Development for Youth, Ho Chi Minh City Communist Youth Union, Vietnam (no. 06/2018/HĐ-KHCN-VU').

\section{References}

[1] S. Sarre, L. Määttänen, T. L. J. Tammela, A. Auvinen, and T. J. Murtola, "Postscreening follow-up of the Finnish prostate cancer screening trial on putative prostate cancer risk factors: vitamin and mineral use, male pattern baldness, pubertal development and non-steroidal anti-inflammatory drug use," Scandinavian Journal of Urology, vol. 50, no. 4, pp. 267-273, 2016.

[2] B. R. da Costa, S. Reichenbach, N. Keller et al., "Effectiveness of non-steroidal anti-inflammatory drugs for the treatment of pain in knee and hip osteoarthritis: a network meta-analysis," The Lancet, vol. 390, no. 10090, pp. e21-e33, 2017.

[3] T.-S. Vo, D.-H. Ngo, L. G. Bach, D.-N. Ngo, and S.-K. Kim, "The free radical scavenging and anti-inflammatory activities of gallate-chitooligosaccharides in human lung epithelial A549 cells," Process Biochemistry, vol. 54, pp. 188-194, 2017.

[4] A. K. Nguyen, T. H. Nguyen, B. Q. Bao, L. G. Bach, and D. H. Nguyen, "Efficient self-assembly of mPEG end-capped porous silica as a redox-sensitive nanocarrier for controlled doxorubicin delivery," International Journal of Biomaterials, vol. 2018, Article ID 1575438, 8 pages, 2018.

[5] T. D. Březinova, J. Vymazal, M. Koželuh, and L. Kule, "Occurrence and removal of ibuprofen and its metabolites in full-scale constructed wetlands treating municipal wastewater," Ecological Engineering, vol. 120, pp. 1-5, 2018.

[6] S. Adityosulindro, C. Julcour, and L. Barthe, "Heterogeneous Fenton oxidation using Fe-ZSM5 catalyst for removal of ibuprofen in wastewater," Journal of Environmental Chemical Engineering, vol. 6, no. 5, pp. 5920-5928, 2018.

[7] H. A. Hasan, S. R. S. Abdullah, A. W. N. Al-Attabi et al., "Removal of ibuprofen, ketoprofen, COD and nitrogen compounds from pharmaceutical wastewater using aerobic suspension-sequencing batch reactor (ASSBR)," Separation and Purification Technology, vol. 157, pp. 215-221, 2016.

[8] S. Saeid, P. Tolvanen, N. Kumar et al., "Advanced oxidation process for the removal of ibuprofen from aqueous solution: a non-catalytic and catalytic ozonation study in a semi-batch reactor," Applied Catalysis B: Environmental, vol. 230, pp. 77-90, 2018.

[9] Y. Luo, W. Guo, H. H. Ngo et al., "A review on the occurrence of micropollutants in the aquatic environment and their fate and removal during wastewater treatment," Science of the Total Environment, vol. 473-474, pp. 619-641, 2014.

[10] T. Van Thuan, B. T. P. Quynh, T. D. Nguyen, V. T. T. Ho, and L. G. Bach, "Response surface methodology approach for optimization of $\mathrm{Cu}^{2+}, \mathrm{Ni}^{2+}$ and $\mathrm{Pb}^{2+}$ adsorption using $\mathrm{KOH}-$ activated carbon from banana peel," Surfaces and Interfaces, vol. 6, pp. 209-217, 2017.

[11] T. Van Tran, Q. T. P. Bui, T. D. Nguyen, N. T. H. Le, and L. G. Bach, "A comparative study on the removal efficiency of metal ions $\left(\mathrm{Cu}^{2+}, \mathrm{Ni}^{2+}\right.$, and $\left.\mathrm{Pb}^{2+}\right)$ using sugarcane bagasse- 
derived $\mathrm{ZnCl}_{2}$-activated carbon by the response surface methodology," Adsorption Science \& Technology, vol. 35, no. 1-2, pp. 72-85, 2017.

[12] T. Van Tran, Q. T. P. Bui, T. D. Nguyen, V. T. T. Ho, and L. G. Bach, "Application of response surface methodology to optimize the fabrication of $\mathrm{ZnCl}_{2}$-activated carbon from sugarcane bagasse for the removal of $\mathrm{Cu}^{2+}$," Water Science and Technology, vol. 75, no. 9, pp. 2047-2055, 2017.

[13] H. N. Tran, Y.-F. Wang, S.-J. You, and H.-P. Chao, "Insights into the mechanism of cationic dye adsorption on activated charcoal: the importance of $\pi-\pi$ interactions," Process Safety and Environmental Protection, vol. 107, pp. 168-180, 2017.

[14] H. N. Tran, H.-P. Chao, and S.-J. You, "Activated carbons from golden shower upon different chemical activation methods: synthesis and characterizations," Adsorption Science \& Technology, vol. 36, no. 1-2, pp. 95-113, 2018.

[15] S.-A. Sajjadi, A. Mohammadzadeh, H. N. Tran et al., "Efficient mercury removal from wastewater by pistachio wood wastesderived activated carbon prepared by chemical activation using a novel activating agent," Journal of Environmental Management, vol. 223, pp. 1001-1009, 2018.

[16] T. V. Pham, T. T. Nguyen, D. T. Nguyen et al., "The preparation and characterization of expanded graphite via microwave irradiation and conventional heating for the purification of oil contaminated water," Journal of Nanoscience and Nanotechnology, vol. 19, no. 2, pp. 1122-1125, 2019.

[17] P. Boakye, H. N. Tran, D. S. Lee, and S. H. Woo, "Effect of water washing pretreatment on property and adsorption capacity of macroalgae-derived biochar," Journal of Environmental Management, vol. 233, pp. 165-174, 2019.

[18] S. Sabale, V. Jadhav, V. Khot, X. Zhu, M. Xin, and H. Chen, "Superparamagnetic $\mathrm{MFe}_{2} \mathrm{O}_{4}(\mathrm{M}=\mathrm{Ni}, \mathrm{Co}, \mathrm{Zn}, \mathrm{Mn})$ nanoparticles: synthesis, characterization, induction heating and cell viability studies for cancer hyperthermia applications," Journal of Materials Science: Materials in Medicine, vol. 26, no. 3, p. 127, 2015

[19] B. Q. Bao, N. H. Le, D. H. T. Nguyen et al., "Evolution and present scenario of multifunctionalized mesoporous nanosilica platform: a mini review," Materials Science and Engineering: C, vol. 91, pp. 912-928, 2018.

[20] S. Singh, M. B. Bahari, B. Abdullah et al., "Bi-reforming of methane on Ni/SBA-15 catalyst for syngas production: influence of feed composition," International Journal of Hydrogen Energy, vol. 43, no. 36, pp. 17320-17243, 2018.

[21] S. Zhao, Z. Zhang, G. Sèbe et al., "Multiscale assembly of superinsulating silica aerogels within silylated nanocellulosic scaffolds: improved mechanical properties promoted by nanoscale chemical compatibilization," Advanced Functional Materials, vol. 25, no. 15, pp. 2326-2334, 2015.

[22] H. Q. Pham, T. T. Huynh, A. Van Nguyen, T. Van Thuan, L. G. Bach, and V. T. Thanh Ho, "Advanced $\mathrm{Ti}_{0.7} \mathrm{~W}_{0.3} \mathrm{O}_{2}$ nanoparticles prepared via solvothermal process using titanium tetrachloride and tungsten hexachloride as precursors," Journal of Nanoscience and Nanotechnology, vol. 18, no. 10, pp. 7177-7182, 2018.

[23] D. W. Kim, L. G. Bach, S.-S. Hong, C. Park, and K. T. Lim, “A facile route towards the synthesis of $\mathrm{Fe}_{3} \mathrm{O}_{4}$ /graphene oxide nanocomposites for environmental applications," Molecular Crystals and Liquid Crystals, vol. 599, no. 1, pp. 43-50, 2014.

[24] Y. V. Kaneti, J. Tang, R. R. Salunkhe et al., "Nanoarchitectured design of porous materials and nanocomposites from metalorganic frameworks," Advanced Materials, vol. 29, no. 12, article 1604898, 2017.
[25] M.-H. Sun, S.-Z. Huang, L.-H. Chen et al., “Applications of hierarchically structured porous materials from energy storage and conversion, catalysis, photocatalysis, adsorption, separation, and sensing to biomedicine," Chemical Society Reviews, vol. 45, no. 12, pp. 3479-3563, 2016.

[26] L. G. Bach, V. T. T. Ho, B. T. P. Quynh, K. T. Lim, and T. C. Anh, "Synthesis of well-defined amphiphilic diblock copolymer brushes on halloysite nanotubes via surfaceinitiated reversible addition-fragmentation chain transfer polymerization," Journal of Nanoscience and Nanotechnology, vol. 17, no. 8, pp. 5834-5838, 2017.

[27] H. V. Dang, Y. T. N. Le, D. T. M. Tran, A. N. Q. Phan, and N. T. S. Phan, "Synthesis of benzo[1,4]thiazines via ring expansion of 2-aminobenzothiazoles with terminal alkynes under metal-organic framework catalysis," Catalysis Letters, vol. 148, no. 5, pp. 1383-1395, 2018.

[28] V. D. Nguyen, C. K. Nguyen, K. N. Tran et al., "Zeolite imidazolate frameworks in catalysis: synthesis of benzimidazoles via cascade redox condensation using Co-ZIF-67 as an efficient heterogeneous catalyst," Applied Catalysis A: General, vol. 555, pp. 20-26, 2018.

[29] T. V. Tran, H. T. N. Le, H. Q. Ha et al., "A five coordination $\mathrm{Cu}$ (II) cluster-based MOF and its application in the synthesis of pharmaceuticals via $\mathrm{sp}^{3} \mathrm{C}-\mathrm{H} / \mathrm{N}-\mathrm{H}$ oxidative coupling," Catalysis Science \& Technology, vol. 7, no. 16, pp. 3453-3458, 2017.

[30] H. T. N. Le, T. V. Tran, N. T. S. Phan, and T. Truong, "Efficient and recyclable $\mathrm{Cu}_{2}(\mathrm{BDC})_{2}(\mathrm{BPY})$-catalyzed oxidative amidation of terminal alkynes: role of bipyridine ligand," Catalysis Science \& Technology, vol. 5, no. 2, pp. 851-859, 2015.

[31] Y.-Z. Chen, R. Zhang, L. Jiao, and H.-L. Jiang, "Metal-organic framework-derived porous materials for catalysis," Coordination Chemistry Reviews, vol. 362, pp. 1-23, 2018.

[32] Z. Yan, W. Zhang, J. Gao et al., "Reverse-phase high performance liquid chromatography separation of positional isomers on a MIL-53(Fe) packed column," RSC Advances, vol. 5, no. 50, pp. 40094-40102, 2015.

[33] N. D. Trinh and S.-S. Hong, "Photocatalytic decomposition of methylene blue over MIL-53(Fe) prepared using microwaveassisted process under visible light irradiation," Journal of Nanoscience and Nanotechnology, vol. 15, no. 7, pp. 54505454, 2015.

[34] S. H. Doan, K. D. Nguyen, T. T. Nguyen, and N. T. S. Phan, "Direct arylation of benzoazoles with aldehydes utilizing metal-organic framework $\mathrm{Fe}_{3} \mathrm{O}(\mathrm{BDC})_{3}$ as a recyclable heterogeneous catalyst," RSC Advances, vol. 7, no. 3, pp. 14231431, 2017.

[35] H. L. Nguyen, "The chemistry of titanium-based metalorganic frameworks," New Journal of Chemistry, vol. 41, no. 23, pp. 14030-14043, 2017.

[36] P. H. Pham, S. H. Doan, H. T. T. Tran et al., "A new transformation of coumarins via direct $\mathrm{C}-\mathrm{H}$ bond activation utilizing an iron-organic framework as a recyclable catalyst," Catalysis Science \& Technology, vol. 8, no. 5, pp. 1267-1271, 2018.

[37] Y. Zhang, G. Li, H. Lu, Q. Lv, and Z. Sun, "Synthesis, characterization and photocatalytic properties of MIL-53(Fe)graphene hybrid materials," RSC Advances, vol. 4, no. 15, pp. 7594-7600, 2014.

[38] T. H. Tu, P. T. N. Cam, L. V. T. Huy, M. T. Phong, H. M. Nam, and N. H. Hieu, "Synthesis and application of graphene oxide aerogel as an adsorbent for removal of dyes from water," Materials Letters, vol. 238, pp. 134-137, 2019.

[39] T. V. Tran, D. T. C. Nguyen, H. T. N. Le et al., "MIL-53 (Fe)directed synthesis of hierarchically mesoporous carbon and its 
utilization for ciprofloxacin antibiotic remediation," Journal of Environmental Chemical Engineering, vol. 7, no. 1, article 102881, 2019.

[40] J.-J. Du, Y.-P. Yuan, J.-X. Sun et al., "New photocatalysts based on MIL-53 metal-organic frameworks for the decolorization of methylene blue dye," Journal of Hazardous Materials, vol. 190, no. 1-3, pp. 945-951, 2011.

[41] W. Lu, Z. Wei, Z.-Y. Gu et al., "Tuning the structure and function of metal-organic frameworks via linker design," Chemical Society Reviews, vol. 43, no. 16, pp. 5561-5593, 2014.

[42] V. T. Tran, D. T. Nguyen, V. T. T. Ho, P. Q. H. Hoang, P. Q. Bui, and L. G. Bach, "Efficient removal of $\mathrm{Ni}_{2}$ ions from aqueous solution using activated carbons fabricated from rice straw and tea waste," Journal of Materials and Environmental Science, vol. 8, pp. 426-437, 2017.

[43] T. Van Thuan, V. T. T. Ho, N. D. Trinh, N. T. Thuong, B. T. P. Quynh, and L. G. Bach, "Facile one-spot synthesis of highly porous $\mathrm{KOH}$-activated carbon from rice husk: response surface methodology approach," Carbon-Science and Technology, vol. 8, pp. 63-69, 2016.

[44] P. Samoila, C. Cojocaru, I. Cretescu et al., "Nanosized spinel ferrites synthesized by sol-gel autocombustion for optimized removal of azo dye from aqueous solution," Journal of Nanomaterials, vol. 2015, Article ID 713802, 13 pages, 2015.

[45] T. V. Tran, V. D. Cao, V. H. Nguyen et al., "MIL-53 (Fe) derived magnetic porous carbon as a robust adsorbent for the removal of phenolic compounds under the optimized conditions," Journal of Environmental Chemical Engineering, vol. 7, article 102902, 2019.

[46] J. Gordon, H. Kazemian, and S. Rohani, "Rapid and efficient crystallization of MIL-53(Fe) by ultrasound and microwave irradiation," Microporous and Mesoporous Materials, vol. 162, pp. 36-43, 2012.

[47] P. Horcajada, T. Chalati, C. Serre et al., "Porous metalorganic-framework nanoscale carriers as a potential platform for drug delivery and imaging," Nature Materials, vol. 9, no. 2, pp. 172-178, 2010.

[48] L. G. Bach, T. Van Tran, T. D. Nguyen, T. Van Pham, and S. T. Do, "Enhanced adsorption of methylene blue onto graphene oxide-doped $\mathrm{XFe}_{2} \mathrm{O}_{4} \quad(\mathrm{X}=\mathrm{Co}, \mathrm{Mn}, \mathrm{Ni})$ nanocomposites: kinetic, isothermal, thermodynamic and recyclability studies," Research on Chemical Intermediates, vol. 44, no. 3, pp. 1661-1687, 2018.

[49] T. A. Vu, G. H. Le, C. D. Dao et al., "Arsenic removal from aqueous solutions by adsorption using novel MIL-53(Fe) as a highly efficient adsorbent," RSC Advances, vol. 5, no. 7, pp. 5261-5268, 2015.

[50] R. Liang, F. Jing, L. Shen, N. Qin, and L. Wu, "MIL-53(Fe) as a highly efficient bifunctional photocatalyst for the simultaneous reduction of $\mathrm{Cr}(\mathrm{VI})$ and oxidation of dyes," Journal of Hazardous Materials, vol. 287, pp. 364-372, 2015.

[51] P. Serra-Crespo, E. Gobechiya, E. V. Ramos-Fernandez et al., "Interplay of metal node and amine functionality in $\mathrm{NH}_{2}$ MIL-53: modulating breathing behavior through intraframework interactions," Langmuir, vol. 28, no. 35, pp. 12916-12922, 2012.

[52] M.-T. H. Nguyen and Q.-T. Nguyen, "Efficient refinement of a metal-organic framework MIL-53(Fe) by UV-vis irradiation in aqueous hydrogen peroxide solution," Journal of Photochemistry and Photobiology A: Chemistry, vol. 288, pp. 55-59, 2014.

[53] S.-S. Li, W.-Y. Zhou, M. Jiang et al., "Insights into diverse performance for the electroanalysis of $\mathrm{Pb}$ (II) on $\mathrm{Fe}_{2} \mathrm{O}_{3}$ nanorods and hollow nanocubes: toward analysis of adsorption sites," Electrochimica Acta, vol. 288, pp. 42-51, 2018.

[54] H. N. Tran, C.-C. Lin, S. H. Woo, and H.-P. Chao, "Efficient removal of copper and lead by $\mathrm{Mg} / \mathrm{Al}$ layered double hydroxides intercalated with organic acid anions: adsorption kinetics, isotherms, and thermodynamics," Applied Clay Science, vol. 154, pp. 17-27, 2018.

[55] H. N. Tran, P. V. Viet, and H.-P. Chao, "Surfactant modified zeolite as amphiphilic and dual-electronic adsorbent for removal of cationic and oxyanionic metal ions and organic compounds," Ecotoxicology and Environmental Safety, vol. 147, pp. 55-63, 2018.

[56] M. A. Bezerra, R. E. Santelli, E. P. Oliveira, L. S. Villar, and L. A. Escaleira, "Response surface methodology (RSM) as a tool for optimization in analytical chemistry," Talanta, vol. 76, no. 5, pp. 965-977, 2008. 

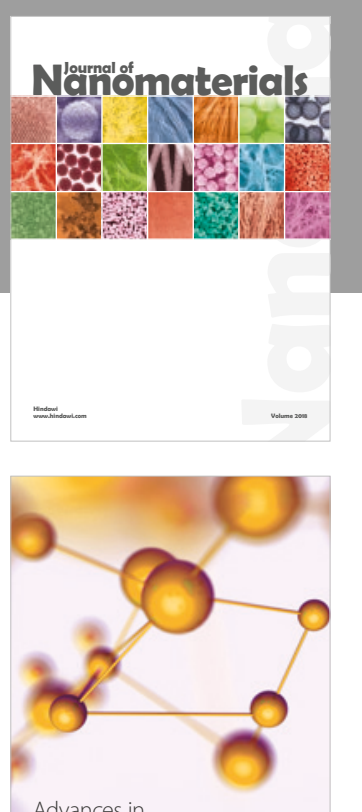

Physical Chemistry
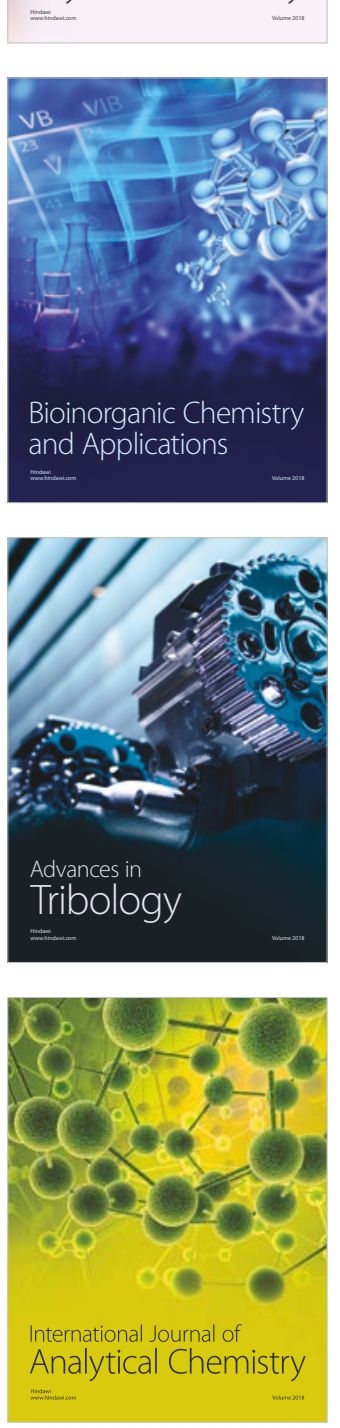

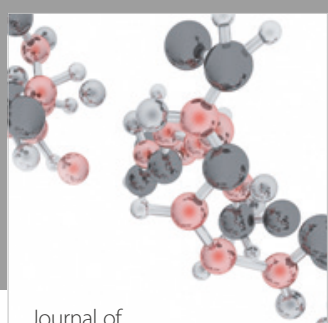

Analytical Methods

in Chemistry

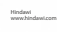

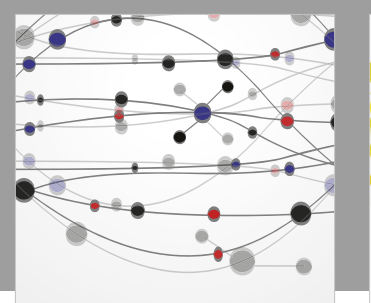

The Scientific World Journal

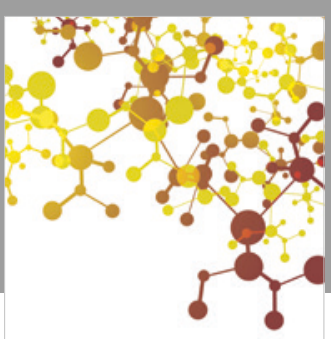

Journal of

Applied Chemistry
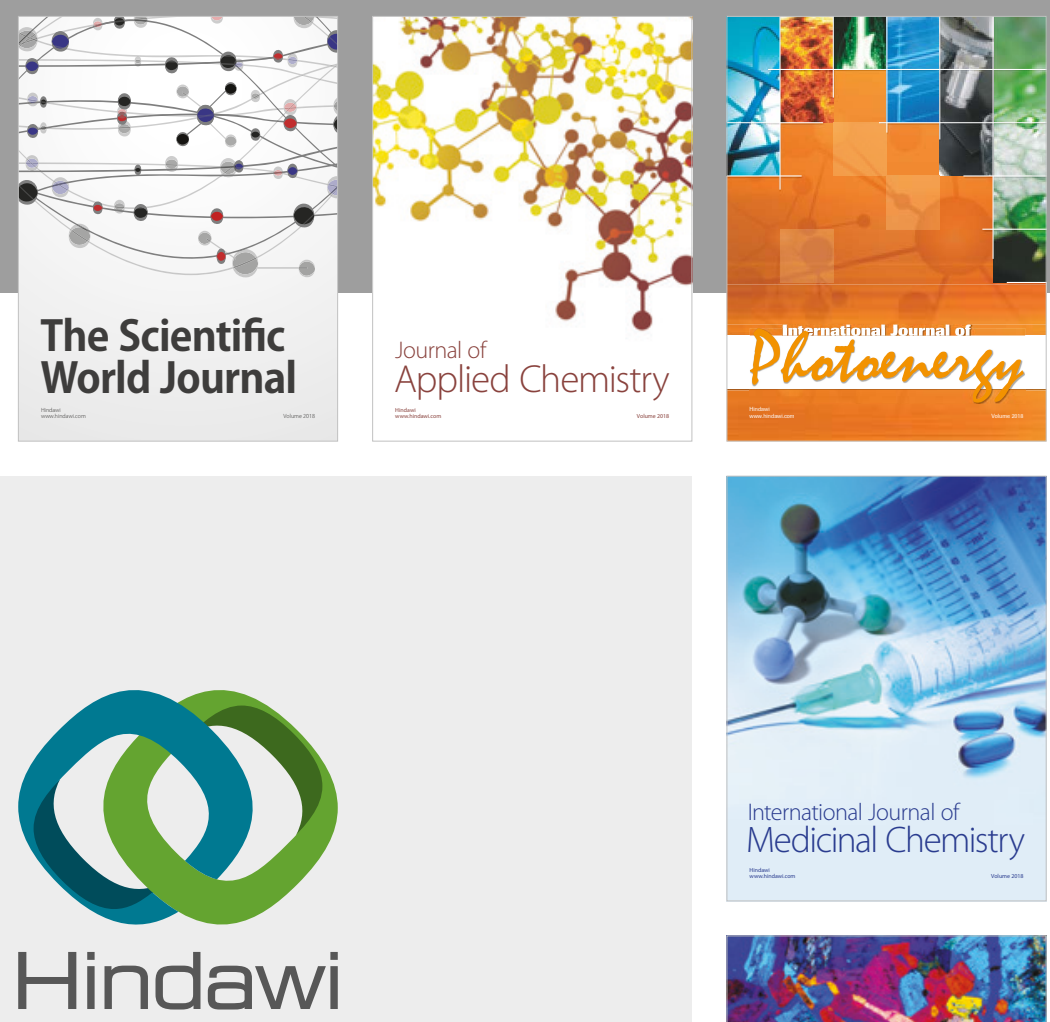

Submit your manuscripts at

www.hindawi.com
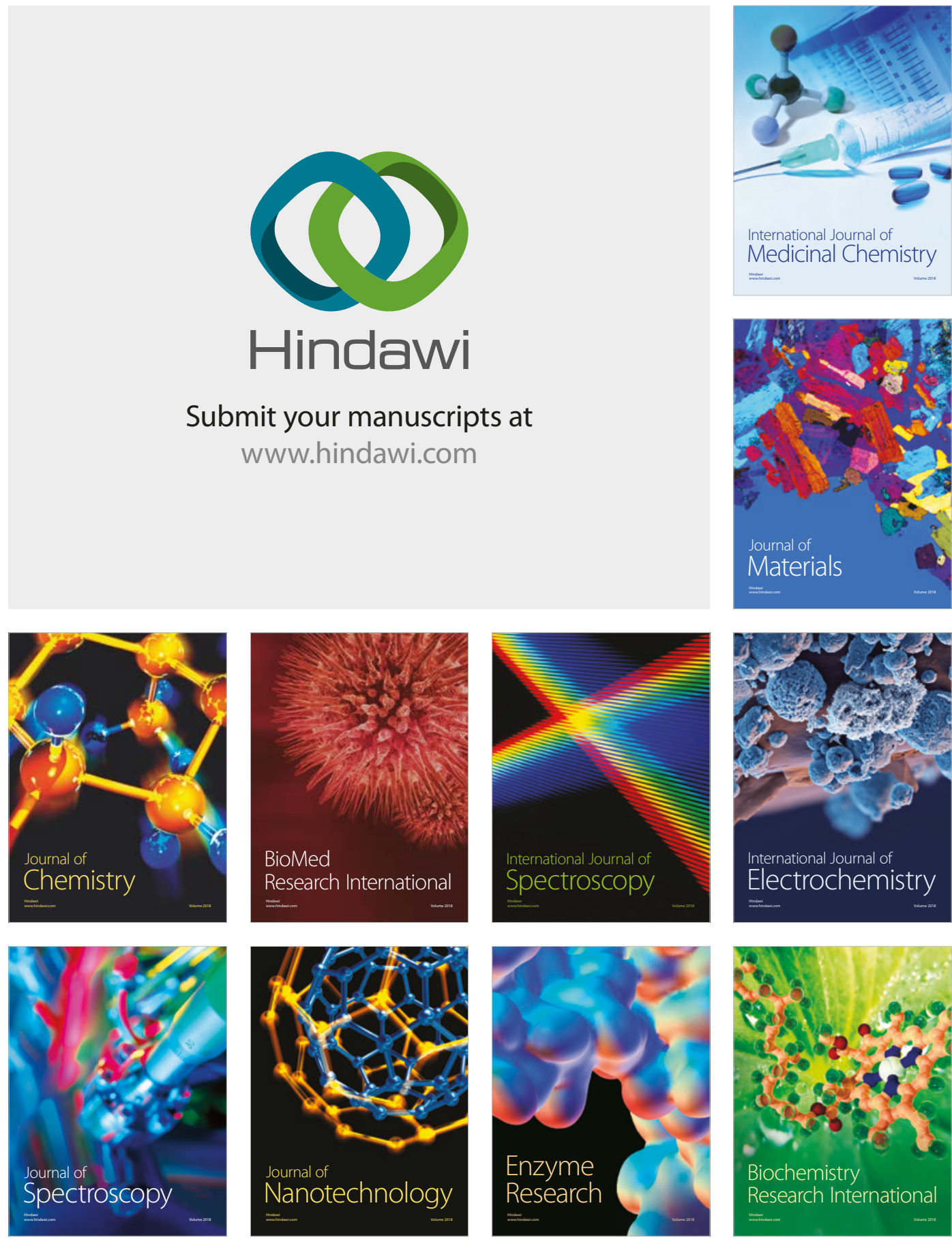
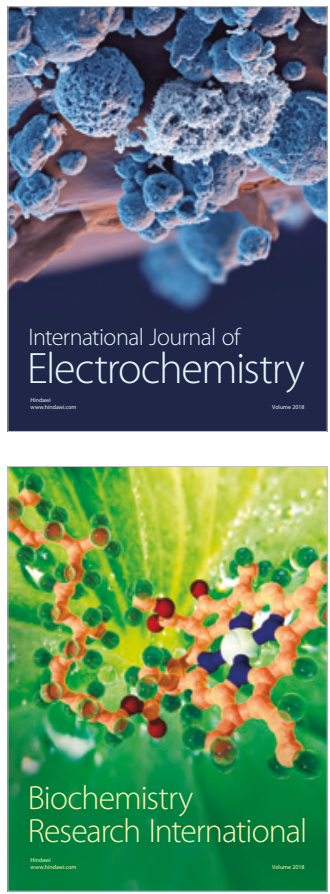